\title{
Drug or Chemical by Structure
}

National Cancer Institute

\section{Source}

National Cancer Institute. Drug or Chemical by Structure. NCI Thesaurus. Code C1913.

Substances that are grouped or classified by chemical composition. 